\title{
BIODIESEL DE BABAÇU (Orbignya sp.) OBTIDO POR VIA ETANÓLICA
}

\author{
José Renato de Oliveira Lima, Rondenelly Brandão da Silva, Carmem Cícera Maria da Silva, Lucas Samuel Soares \\ dos Santos, José Ribeiro dos Santos Jr., Edmilson Miranda Moura e Carla Verônica Rodarte de Moura* \\ Departamento de Química, Universidade Federal do Piauí, 64049-550 Teresina - PI, Brasil
}

Recebido em 4/4/06; aceito em 21/8/06; publicado na web em 19/1/07

\begin{abstract}
BIODIESEL FROM BABASSU (Orbignya $s p$.) SYNTHESIZED VIA ETHANOLIC ROUTE. Biodiesel was obtained by transesterification of babassu oil in anhydrous ethanol and methanol, employing $\mathrm{NaOH}$ as catalyst. The products obtained were characterized by physico-chemical and thermogravimetric analysis. It could be concluded that the properties of the two types of biodiesel (ethanolic and methanolic) are very similar when compared with diesel oil.
\end{abstract}

Keywords: thermogravimetry; Orbignya $s p . ;$ transesterification.

\section{INTRODUÇÃO}

A maior parte de toda a energia consumida no mundo provém do petróleo, carvão e do gás natural. Entretanto, essas são fontes não renováveis e possuem previsão de esgotamento em um futuro próximo ${ }^{1}$. Além disso, os combustíveis fósseis são muito poluidores afetando o meio ambiente de forma bastante agressiva, o que faz a população mundial buscar soluções para tais problemas.

Os óleos vegetais, como alternativa de combustível, começaram a ser estudados no final do século XIX por R. Diesel, sendo que estes eram usados in natura, ou seja, na forma de óleo. Mas o uso direto nos motores apresenta muitos problemas, como por ex.: acúmulo de material oleoso nos bicos de injeção, a queima do óleo é incompleta, forma depósitos de carvão na câmara de combustão, o rendimento de potência é baixo e, como resultado da queima, libera a acroleína (propenal) que é tóxica ${ }^{2}$. Porém, alternativas têm sido consideradas para melhorar o desempenho de óleos vegetais em motores do ciclo diesel, como por ex., diluição, micro-emulsão com metanol ou etanol, craqueamento catalítico e reação de transesterificação com álcoois de cadeia pequena. Dentre essas alternativas, a reação de transesterificação tem sido a mais usada, visto que o processo é relativamente simples e o produto obtido (biodiesel) possui propriedades muito similares às do petrodiesel ${ }^{2}$.

O uso de biodiesel como combustível vem crescendo aceleradamente no mundo inteiro, pois a cadeia de produção deste combustível tem um potencial promissor em vários setores, tais como, social, ambiental e tecnológico ${ }^{3,4}$. O biodiesel abre oportunidades de geração de emprego no campo $^{5}$, valorizando a mão de obra rural, bem como no setor industrial valorizando a mão de obra especializada na produção do combustível. Quanto ao aspecto ambiental a contribuição é grande, visto que haverá uma redução significativa e quantitativa de níveis de poluição ambiental, pois o biodiesel está livre de enxofre e de compostos aromáticos, emite menor índice de particulados, como $\mathrm{HC}, \mathrm{CO}$ e $\mathrm{CO}_{2}$, não é tóxico, é biodegradável, é oriundo de fontes renováveis ${ }^{6} \mathrm{e}$, com isso, o mundo poderá se beneficiar com menor emissão de carbono. No que tange ao aspecto tecnológico, os testes de desempenho de motores realizados na década de 80 com uso de $100 \%$ de biodiesel mostraram-se bastante satisfatórios, pois não apresentaram problemas significativos ${ }^{7}$. Hoje a intenção do Brasil é de se usar uma proporção

*e-mail: carla@ufpi.br de 2 a $5 \%$ de biodiesel misturado ao diesel de petróleo, o que não causará mudanças significativas no desempenho dos motores e nem adaptações aos mesmos. Entretanto, a demanda nacional na produção de óleos vegetais crescerá em 50\%, pois o Brasil consome cerca de 36 bilhões de L/ano de diesel e se misturar cerca de 5\% de biodiesel no petrodiesel, haverá uma necessidade de aproximadamente 3,5 bilhões de L/ano de óleo vegetal ${ }^{8}$.

No aspecto do aumento da produção de óleos vegetais, o Brasil possui em torno de 150 milhões de ha que poderão ser incorporados à produção agrícola, sendo 90 milhões referentes às novas fronteiras e 60 milhões às terras e pastagens ${ }^{9}$. Essa área está distribuída em todo o território nacional e a produção de oleaginosa implica em fatores edofoclimáticos e o Brasil é bastante diverso neste aspecto. Sendo assim, culturas como as de soja, milho, amendoim, girassol, mamona, babaçu, palma etc, poderão ser exploradas para fins de produção deste biocombustível ${ }^{10}$. O Nordeste brasileiro possui uma área de cerca de 12 milhões de ha plantados com babaçu, sendo que a maior parte está concentrada no estado do Maranhão. Mensalmente, são extraídas em torno de 140.000 t de amêndoas destes babaçuais. Contudo, o potencial do babaçu continua inexplorado sendo possível o aproveitamento econômico para produção de carvão, óleo combustível, gás, lubrificante e óleo comestível. No que tange à produção de óleo combustível, o óleo de babaçu possui características excelentes para produção de biodiesel, devido sua composição ser predominantemente láurica (Tabela 1) ${ }^{11}$. Este fato facilita a reação de transesterificação, pois os ésteres láuricos são compostos de cadeias curtas que interagem mais eficaz e efetivamente com o agente transesterificante e com o catalisador, de modo a se obter um produto, biodiesel, de excelentes características físico-químicas, inclusive quando o catalisador

Tabela 1. Composição química do óleo de babaçu

\begin{tabular}{lc}
\hline Ácido graxo & Contribuição percentual \\
\hline Ácido caprílico (C8:0) & $5,0 \%$ \\
Ácido cáprico (C10:0) & $6,0 \%$ \\
Ácido láurico (C12:0) & $44,0 \%$ \\
Ácido mirístico (C14:0) & $17,0 \%$ \\
Ácido palmítico (C16:0) & $8,0 \%$ \\
Ácido esteárico (C18:0) & $4,5 \%$ \\
Ácido oléico (C18:1) & $14,0 \%$ \\
Ácido linoléico (C18:2) & $2,0 \%$ \\
\hline
\end{tabular}


é diferente do $\mathrm{NaOH}$, que é o mais utilizado. Por ex., a literatura ${ }^{12}$ mostra que, quando se usa catalisadores heterogêneos e óleo de babaçu para síntese de biodiesel, se obtêm maiores rendimentos em relação ao outros óleos.

$\mathrm{Na}$ transesterificação de óleos vegetais, Figura 1, um triglicerídeo reage com um álcool (metanol ou etanol) na presença de um catalisador que pode ser ácido, básico, metálico ou biológico, produzindo uma mistura de ésteres alquílicos de ácidos graxos e glicerol ${ }^{13}$, sendo que a mistura de ésteres é o que se denomina biodiesel.

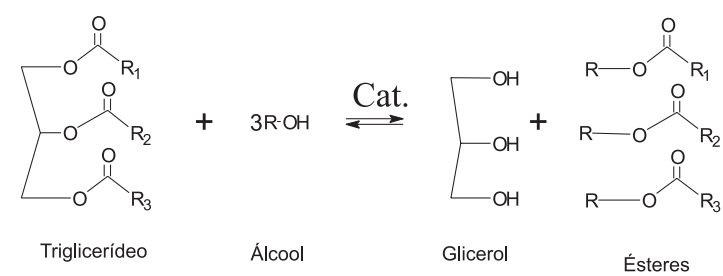

Figura 1. Transesterificação de triacilgliceróis (triglicerídeos)

A tendência mundial é de se realizar a transesterificação em meio básico, por questões econômicas e tecnológicas ${ }^{14}$. O álcool mais utilizado é o metanol, derivado do petróleo, devido às facilidades cinéticas que proporciona à reação. Entretanto, o Brasil é um dos maiores produtores de álcool etílico, oriundo da biomassa, no mundo e este é um fator que estimula estudos de seu uso em substituição ao metanol.

Nesse contexto, objetivou-se a obtenção de biodiesel de babaçu utilizando metanol e etanol como agentes transesterificantes e hidróxido de sódio como catalisador, visando estudar o rendimento da reação e, ainda, caracterizar o produto obtido segundo parâmetros físicos-químicos e, também, através de técnica termogravimétrica.

\section{PARTE EXPERIMENTAL}

\section{Materiais e métodos}

Os álcoois metílicos e etílicos da marca Qeel e o hidróxido de potássio adquirido da Vetec foram de pureza analítica e usados sem nenhuma purificação prévia. O óleo de babaçu refinado foi adquirido no comércio local.

As caracterizações químicas, como teor de alcalinidade, acidez e glicerina foram realizadas segundo as normas do Instituto Adolfo Lutz ${ }^{15}$ e "United States Pharmacopeial-USP"16.
A viscosidade foi medida utilizando-se um tubo viscosimétrico cinemático Cannon Fensk 350 em banho térmico Koehler KV3000 de acordo com NBR 10441. A densidade foi medida em um densímetro automático Anton Paar DMA 4500 seguindo a norma ASTM D 4052; o teor de enxofre foi determinado por raios-X, em equipamento Horiba SLFA $1800 \mathrm{H}$, como orienta a norma ASTM D 4294; o ponto de fulgor foi medido em um Pensky Martens HFP 380 vaso fechado, de acordo com a norma ASTM D 93. As análises termogravimétricas dos biodieseis foram realizadas em Termobalança TA Instrumentos modelo TGA-2050, com taxa de aquecimento de $10{ }^{\circ} \mathrm{C} \mathrm{min}-1$, iniciando a corrida em $30{ }^{\circ} \mathrm{C}$ e chegando aos $450{ }^{\circ} \mathrm{C} \mathrm{com}$

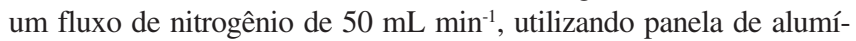
nio de $20 \mu \mathrm{L}$ com furo de aproximandamente $0,5 \mathrm{~mm}$ na tampa e adição de alumina em pó como diluente inerte ${ }^{17}$. A curva termogravimétrica do óleo de babaçu foi obtida em condições iguais àquelas utilizadas para os biodieseis, exceto o limite máximo de temperatura que foi até $550{ }^{\circ} \mathrm{C}$ para que se obtivessem patamares bem definidos na curva termogravimétrica do óleo.

\section{Estatística}

Todas as análises foram realizadas em triplicata e informado o valor da média das medidas e o desvio padrão.

\section{Obtenção de biodiesel via metanólica e etanólica}

A reação de transesterificação foi realizada utilizando-se $100 \mathrm{~g}$ de óleo de babaçu refinado, $20 \mathrm{~g}$ de metanol ou $40 \mathrm{~g}$ de etanol e 0,5 $\mathrm{g}$ de $\mathrm{NaOH}$. A mistura ficou sob agitação à temperatura ambiente por um período de $30 \mathrm{~min}$. A ocorrência da reação foi monitorada através da mudança de cor da mistura reacional e o tempo foi baseado em dados da literatura ${ }^{18}$. A análise de glicerina combinada, segundo método descrito na USP ${ }^{16}$, e a Cromatografia em Camada Delgada - CCD foram utilizadas para verificar a conversão final do óleo em ésteres. Esta mistura foi transferida para um funil de separação de $250 \mathrm{~mL}$, para separação dos ésteres (fase superior) da glicerina (fase inferior). A fase superior foi lavada com várias porções de $50 \mathrm{~mL}$ de água destilada para retirada das impurezas e posteriormente aquecida à $110{ }^{\circ} \mathrm{C}$ para secagem dos ésteres (biodiesel).

\section{RESULTADOS E DISCUSSÃO}

Os resultados das análises físico-químicas estão dispostos na Tabela 2 .

Tabela 2. Características físico-químicas dos biodieseis de babaçu obtidos por via metílica e etílica e algumas especificações legais da Agência Nacional de Petróleo, Gás Natural e Bicombustíveis (ANP)

\begin{tabular}{|c|c|c|c|}
\hline \multirow[t]{2}{*}{ Características físico-químicas } & \multicolumn{2}{|c|}{ Biodiesel } & \multirow[t]{2}{*}{ Resolução ANP n42/04 } \\
\hline & BME & BET & \\
\hline Acidez do óleo in natura (mg KOH/g) & $0,505 \pm 0,004$ & $0,505 \pm 0,004$ & $\mathrm{NC}$ \\
\hline Índice de saponificação do óleo (mg KOH/g) & $233,767 \pm 1,270$ & $233,767 \pm 1,270$ & $\mathrm{NC}$ \\
\hline Alcalinidade livre $(\mathrm{meq} / \mathrm{g})$ & 0,000 & 0,000 & $\mathrm{NC}$ \\
\hline Alcalinidade combinada (meq/g) & $0,004 \pm 0,000$ & $0,006 \pm 0,001$ & $\mathrm{NC}$ \\
\hline Alcalinidade total (meq/g) & $0,004 \pm 0,000$ & $0,006 \pm 0,001$ & $\mathrm{NC}$ \\
\hline Acidez do biodiesel (mg KOH/g) & $0,224 \pm 0,001$ & $0,448 \pm 0,003$ & 0,8 \\
\hline Glicerina livre $(\%)$ & $0,01 \pm 0,00$ & $0,02 \pm 0,00$ & 0,02 \\
\hline Densidade a $20{ }^{\circ} \mathrm{C}\left(\mathrm{g} / \mathrm{cm}^{3}\right)$ & $0,88 \pm 0,00$ & $0,87 \pm 0,00$ & (1) \\
\hline Ponto de fulgor $\left({ }^{\circ} \mathrm{C}\right)$ & $112 \pm 0,6$ & $122 \pm 0,6$ & Min*. 100 \\
\hline Teor de enxofre $(\%)$ & $0,003 \pm 0,001$ & $0,003 \pm 0,001$ & Anotar \\
\hline Viscosidade $40,0 \pm 0,1^{\circ} \mathrm{C}\left(\mathrm{mm}^{2} / \mathrm{s}\right)$ & $4,0 \pm 0,02$ & $3,8 \pm 0,02$ & $\operatorname{Max}^{* *} .6,0$ \\
\hline
\end{tabular}

$\mathrm{NC}=$ Não cita. $(1)=$ Limites para o diesel tipo B: 0,82 a $0,88 \mathrm{~g} / \mathrm{cm}^{3}$. * = Mínimo. ** $=$ Máximo. 


\section{Análises físico-químicas}

Óleo de babaçu in natura Índice de saponificação

O índice de saponificação do óleo de babaçu foi de $233 \mathrm{mg}$ $\mathrm{KOH} / \mathrm{g}$ e é bem maior que o valor encontrado para o óleo de mamona, por ex., $180 \mathrm{mg} \mathrm{KOH/g} \mathrm{em} \mathrm{média}{ }^{19}$. Esta discrepância pode ser explicada pelo fato do óleo de babaçu ser composto por ácidos graxos de menor massa molecular média ${ }^{20}$. $\mathrm{O}$ índice de saponificação encontrado para o óleo de babaçu está compatível com o encontrado na literatura ${ }^{11}$.

\section{Índice de acidez}

O índice de acidez do óleo de babaçu utilizado para a transesterificação foi de $0,505 \pm 0,004 \mathrm{mg} \mathrm{KOH} / \mathrm{g}$. Este é um valor adequado para transformação do óleo em biodiesel, visto que um excesso de ácidos graxos livres, quando se usa hidróxidos como catalisador, levaria a reações de saponificação competindo com a reação de transesterificação.

\section{Biodiesel de babaçu}

O rendimento da reação foi de $71,8 \%$ em massa, quando se usou metanol e de $62,2 \%$ quando se usou etanol.

Houve perda de $15,6 \%$ (metanol) e de $22,3 \%$ (etanol) em relação à formação dos produtos, o que pode ser atribuído à formação de sabão e carreio durante a etapa de purificação do biodiesel. $\mathrm{O}$ valor das perdas, principalmente a formação de sabão, pode ser devido aos álcoois utilizados não serem anidros, visto que os mesmos foram utilizados sem purificação prévia e a água é um dos agentes causadores de reações paralelas de saponificação ${ }^{21}$, com isto o sabão consome o catalisador e reduz a eficiência da reação de transesterificação ${ }^{22}$.

A alcalinidade livre medida para os biodieseis ficou em torno de $0,01 \%$, pois nas etapas de purificação os biodieseis são lavados com água e o catalisador é carreado neste solvente.

$\mathrm{O}$ índice de acidez foi de $0,224 \mathrm{mg} \mathrm{KOH} / \mathrm{g}$ (metanol) e 0,448 $\mathrm{mg} \mathrm{KOH} / \mathrm{g}$ (etanol); estes valores satisfazem as exigências da resolução 042 da $\mathrm{ANP}^{23}$.

A análise de glicerina livre no biodiesel de babaçu comprovou a eficiência da purificação, uma vez que os resultados obtidos atendem a legislação que estabelece uma tolerância de, no máximo, $0,02 \%$ de glicerina livre no biodiesel.

Os valores encontrados para os parâmetros de viscosidade e de densidade foram de 4,0 $\pm 0,02 \mathrm{cSt}$ (metanol) e de 3,8 $\pm 0,02 \mathrm{cSt}$ (etanol) e $0,88 \pm 0,00 \mathrm{~g} / \mathrm{cm}^{3}$ (metanol) e $0,87 \pm 0,00 \mathrm{~g} / \mathrm{cm}^{3}$ (etanol), respectivamente. Tais valores são compatíveis com os normatizados para o diesel mineral (Tabela 2). O ponto de fulgor, temperatura mínima na qual os combustíveis entram em combustão, na presença de chama, foi de $112 \pm 0,6^{\circ} \mathrm{C}$ (metanol) e $122 \pm 0,6{ }^{\circ} \mathrm{C}$ (etanol). Esses valores estão acima do valor mínimo permitido pela Resolução 042 da ANP. Isto significa que se o ponto de fulgor aumenta, também aumentará a segurança no manuseio dos biodieseis em relação ao diesel, que entra em combustão em torno de $76{ }^{\circ} \mathrm{C}^{24}$.

$\mathrm{O}$ teor de enxofre, apresentado na Tabela 2, não é normatizado pela ANP, para o biodiesel, entretanto a ANP recomenda que seja analisado em conjunto com as demais características e que lhe sejam informados os resultados para que ela possa monitorar a ocorrência de enxofre no biodiesel ${ }^{23}$.

\section{Análises termogravimétricas}

Para que o biodiesel seja usado como substituto do diesel mineral é necessário garantir que a qualidade e as propriedades deste combustível sejam confiáveis e consistentes com padrões de quali- dade exigidos por normas ${ }^{25}$. O ponto de ebulição é uma propriedade importante para o biodiesel, como é para o controle de qualidade da indústria de diesel de petróleo ${ }^{25}$. Além disso, através do ponto de ebulição é possível prever propriedades como pressão de vapor, densidade, calor latente, calor de vaporização, viscosidade e tensão superficial do biodiesel ${ }^{25}$. O biodiesel, como é mistura de ésteres metílicos ou etílicos, terá suas propriedades físicas análogas àquelas dos ésteres puros. Propriedades como ponto de ebulição ou volatilidade são dependentes da composição dos ácidos graxos, principalmente do comprimento da cadeia e do número de insaturações presentes ${ }^{26}$. A análise termogravimétrica-TG é uma técnica rápida para medir a pressão de vapor e ponto de ebulição de compostos orgânicos, incluindo triglicerídeos e mostra resultados precisos $( \pm 5 \%)$. Não há evidência de decomposição térmica quando a medida do ponto de ebulição e pressão de vapor é realizada por TG a $1 \mathrm{~atm}^{17,27}$. A Figura 2 mostra a curva termogravimétrica do óleo de babaçu in natura e pode-se notar uma perda de massa de $96,46 \%$, com uma temperatura "on set" em $397,26{ }^{\circ} \mathrm{C}$, que pode ser atribuída a uma única substância ou a uma mistura com pequenas diferenças de massas moleculares.

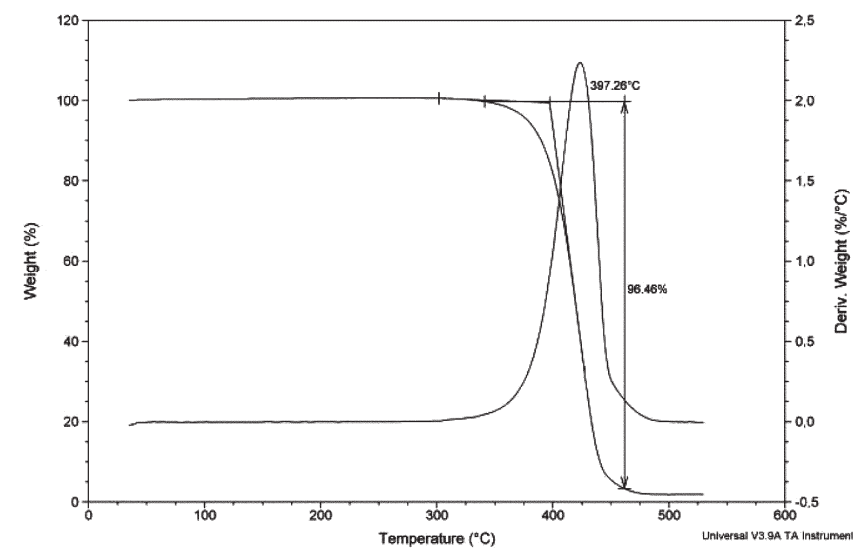

Figura 2. Curva termogravimétrica do óleo de babaçu in natura

Quando se comparam as curvas termogravimétricas dos biodieseis metílico (BME) e etílico (BET), observa-se um comportamento térmico similar, em termos de percentuais de perda de massa e faixa de temperatura, o que já era esperado, visto que a composição dos ésteres metílicos e etílicos é bastante parecida, como pode ser visto na Figura 3.

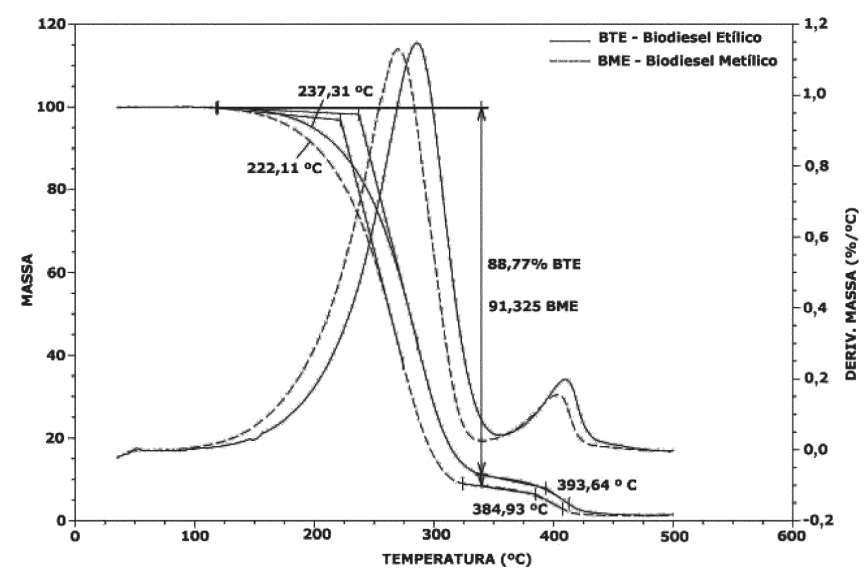

Figura 3. Curva termogravimétrica dos biodieseis de babaçu BME e BET

Nas curvas termogravimétricas dos biodieseis BME e BET (Figura 3), verificou-se duas perdas de massa nas seguintes tempera- 
turas 218,29 e $379,63{ }^{\circ} \mathrm{C}$ e 235,47 e $388,46{ }^{\circ} \mathrm{C}$, respectivamente. Os maiores patamares de perdas de massas nas curvas dos biodieseis BME e BET corresponderam a 92,06 e 89,69\%, respectivamente, e podem ser atribuídos às misturas de ésteres metílicos e etílicos, derivados de ácidos graxos de cadeias carbônicas variando de quatro a dezoito átomos de carbono, os quais possuem pontos de ebulição que vão de 193 (C8:0) a $352^{\circ} \mathrm{C}(\mathrm{C} 18: 0)^{25}$, que fazem parte da constituição do óleo de babaçu. Estas porcentagens de massa estão bastante coerentes, pois enquadram os biodieseis obtidos no parâmetro destilação que estabelece uma temperatura máxima de $360{ }^{\circ} \mathrm{C}$ para uma recuperação de $90 \%$ da massa destilada de biodiesel, de acordo com resolução $n^{\circ} 042$ da ANP.

Além destas perdas de massa, foram observadas outras duas, correspondentes a $8,75 \%$ na curva BME e 10,75\% na curva BET, as quais podem ser atribuídas a um resíduo do óleo in natura (P.E. $397{ }^{\circ} \mathrm{C}$ ) que não reagiu e/ou a ésteres formados por ácidos graxos de cadeias carbônicas insaturadas C18:1, C18:2 e C18:3 que possuem pontos de ebulição médios de 350 a $380{ }^{\circ} \mathrm{C}^{28}$.

Quanto ao uso da alumina, neste caso, não se observou alterações na obtenção das curvas termogravimétricas a não ser um deslocamento das temperaturas "on set" em, aproximadamente, $15{ }^{\circ} \mathrm{C}$ a mais para as corridas feitas sem o uso deste adsorvente.

\section{CONCLUSÃO}

O processo que foi utilizado, neste trabalho, para a obtenção de biodiesel, a partir do óleo de babaçu é uma metodologia já bastante testada e divulgada na literatura. Entretanto, obtiveram-se os biodieseis à temperatura ambiente e os resultados foram satisfatórios, uma vez que se alcançaram rendimentos médios de $67 \%$ em ésteres.

A técnica de termogravimetria utilizada para obter o ponto de ebulição médio dos éteres que compõem os biodieseis é conveniente, visto que é um equipamento barato, comparado ao destilador a vácuo, usa-se pouca amostra e os resultados são confiáveis.

As propriedades físico-químicas dos biodieseis metílicos e etílicos do óleo de babaçu estão de acordo com os limites estabelecidos pela ANP, sendo, nestes termos, possível utilizá-los puros ou misturados ao diesel, em motores a ciclo diesel, sem que seja necessário fazer qualquer adaptação nestas máquinas. Além disso, o biodiesel produzido com etanol tem qualidades tão boas e, às vezes, até melhores que aquelas encontradas para o biodiesel metílico, sendo, portanto um caminho bastante promissor para a rota de produção brasileira.

\section{AGRADECIMENTOS}

À CAPES, ao CNPq e à FAPEPI pela concessão das bolsas de pós-graduação e apoio financeiro, ao LAPETRO da UFPI, pela utilização dos equipamentos e aos Drs. J. M. Moita Neto e M. H. Chaves pela colaboração no trabalho,

\section{REFERÊNCIAS}

1. Shuchardt, U. F.; Sercheli, R.; Vargas, M.; J. Braz. Chem. Soc. 1998, 9, 190.

2. Gardner, R.; Kazi, S.; Ellis, E. M.; Toxicol. Lett. 2004, 148, 65.

3. Masjuk, H.; Sapuan, M. S.; J. Braz. Chem. Soc. 1995, 12, 609.

4. Srivastava, A.; Prasad, R.; Renew. Sust. Energy Rev. 2000, 4, 111.

5. Holanda, A.; Biodiesel e Inclusão Social, Câmara dos Deputados Federais: Brasília, DF, 2004

6. Lee, S. W.; Herage, T.; Young, B.; Fuel 2004, 83, 1607.

7. Brasil, MIC - Ministério da Indústria e Comércio, Secretaria de Tecnologia Industrial; Produção de combustíveis líquidos a partir de óleos vegetais, STI/CIT: Brasília, 1985.

8. Anuário Brasileiro de Soja, Ed. Gazeta G.C. Santa Cruz do Sul: RS, 2001

9. Informativa Rede baiana de biocombustíveis, $\mathrm{n}^{\mathrm{o}} 72,17 / 03 / 2005$.

10. Costa, R. C. A.; Biomass and Bioenergy 2004, 26, 405.

11. http://www.revistaagroamazonia.com.br, acessada em Novembro 2004.

12. Abreu, F. R.; Lima, D. G.; Hamu, E. H.; Wolf, C.; Suarez, P. A. Z.; J. Mol. Catal. A: Chem. 2004, 209, 29.

13. Ferrari, R. A.; Oliveira, V. S.; Scabio, A.; Quim. Nova 2005, 28, 19.

14. Noureddini, H.; Medikonduru, V. A.; J. Am. Oil Chem. Soc. 1986, 63, 1598.

15. Instituto Adolfo Lutz, Normas analíticas do Instituto Adolfo LutzMétodos químicos e físicos para análise de alimentos, $3^{\mathrm{a}}$ ed., São Paulo, 1985, vol.1, p. 245-250.

16. Estados Unidos, Pharmacopeial Convention, The United States Pharmacopeial the National Formulary: USP 24, NF 19. Rockville: USA, 200, p. 780 .

17. Goodrum, J. W.; Geller, D. P.; Lee, S. A.; Thermochim. Acta 1998, 71, 311.

18. Meher, L. C.; Sagar, D. V.; Naik, S. N.; Renew. Sust. Energy Rev. 2006, 10,248 .

19. Azevedo, D. M. P.; Lima, E. F.; Agronegócio da Mamona no Brasil, Embrapa Informação Tecnológica: Brasília-DF, 2001, p. 91.

20. Moretto, E.; Fett, R.; Tecnologia de Óleos e Gorduras Vegetais, na indústria de alimentos, Livraria Varela: São Paulo, 1998.

21. Ma, F.; Hanna, M. A.; Bioresour. Technol. 1999, 70, 1.

22. Fukuda, H.; Kondo, A.; Noda, H.; J. Biosci. Bioeng. 2001, 92, 405.

23. http://www.anp.gov.br/petro/legis_biodiesel.asp, acessada em Dezembro 2005.

24. Alcântara, R.; Amores, J.; Canoira, L.; Fidalgo, E.; Franco, M. J.; Navarro, A.; Biomass and Bioenergy 2000, 18, 515.

25. Yuan, W.; Hansen, A. C.; Zhang, Q.; Fuel 2005, 84, 943.

26. Goodrum, J. W.; Biomass and Bioenergy 2002, 22, 205.

27. Goodrum J. W.; J. Am. Oil Chem. Soc. 1997, 74, 947.

28. Knothe, G.; Fuel Process. Technol. 2005, 86, 1059. 